\title{
Quantification of Effects of Fly Ash Type on Concrete Early-Age Cracking
}

\author{
by Kyle A. Riding, Jonathan L. Poole, Anton K. Schindler, Maria C. G. Juenger, and Kevin J. Folliard
}

The mechanisms that contribute to early-age cracking are complex. Determining the relative importance of each mechanism as well as the combined cracking potential for a given concrete material is essential for the concrete industry to construct structures with a long service life. A method for quantifying the cracking risk of a concrete mixture is presented. The method involves testing for the concrete heat of hydration, setting time, free thermal and autogenous movement, restrained stress, and mechanical property development. The concrete uniaxial stress under restrained conditions is measured using a rigid cracking frame. This test setup was used to quantify the effects of using fly ash on the concrete cracking risk using four different fly ashes with varying calcium oxide contents. All fly ashes reduced the cracking risk because of the decrease in the heat of hydration of the cementitious materials and, to a lesser extent, the increased early-age creep.

Keywords: cracking; early-age creep; fly ash; mass concrete.

\section{INTRODUCTION}

In recent years, the drive for rapid construction and durable concrete has led to the use of very-high-strength concrete with lower water-cementitious material ratios $(w / \mathrm{cm})$ and higher cementitious contents. At the same time, the size of many concrete bridge members has increased for structural and aesthetic reasons. The increased member size and increased cement content used have drawn concern over the potential risk for thermal and autogenous shrinkage cracking in these members. The last thing that owners want to see is very durable concrete between the cracks when they expect a durable structure.

The causes of restrained concrete cracking can be very complex. The cracking risk is dependent on the structural design, proper materials selection, and good construction practices. The structural design must allow for a reasonable amount of expansion and contraction. The concrete mixture proportions must then be designed to limit the heat of hydration, drying shrinkage, and autogenous shrinkage to acceptable levels for the member. The contractor must then use good construction practices, placement rates, and proper curing that are specific to the type of materials used (for example, concrete with supplementary cementing materials [SCMs] may need extra curing time to prevent cracking).

The selection of concrete materials with a low cracking risk involves many interrelated factors. A comparison of the concrete stress development with the strength development can be used to determine the cracking risk of a mixture. ${ }^{1}$ The stress development is dependent on the volume change, elastic modulus development, and rate of creep. The temperature development, and hence thermal volume change of concrete, depends on the aggregate type used, fresh concrete temperature, cementitious materials used, chemical admixtures, member size and dimensions, and environmental conditions. ${ }^{2}$ The autogenous shrinkage development depends on the temperature, cementitious materials used, and $w / \mathrm{cm}^{3,4}$ The rate of elastic modulus development versus the rate of volume change and location of volume change in the member will determine how much beneficial precompression is developed in the concrete at early ages. ${ }^{5}$ The creep rate depends on the stress level, the concrete age, the materials, the elastic modulus, and the temperature. ${ }^{6,7}$

This paper will focus on a battery of tests that, when performed, will allow the user to ascertain the volume change, creep behavior, and mechanical property development of different concrete mixtures. The results of these tests allow direct quantification of the cracking sensitivity of a specific mixture. The testing regime was then used to examine the effect of fly ash with varying calcium oxide $(\mathrm{CaO})$ levels on concrete cracking sensitivity. The $\mathrm{CaO}$ level of the fly ash has been shown to be an indicator of its cementitious nature and, thus, the amount of heat liberated during hydration. ${ }^{8}$ The following are not well understood: the relative importance of reducing the heat of hydration as compared with the reduction in early-age strength, and the increase in creep and decrease in elastic modulus associated with the use of fly ash. The testing regime described in this paper presents a method of quantifying the benefits of each material property, which can then be used in a varying-restraint-induced stress analysis and modeling of the structure to determine the cracking risk.

\section{RESEARCH SIGNIFICANCE}

Early-age cracking in mass concrete bridge members has become a concern in recent years. Bridge member sizes have increased, increasing the risk of thermal cracking in many structures. Lower $w / \mathrm{cm}$ concretes have been used to produce denser, lower permeability concrete, whereas at the same time increase the risk of autogenous shrinkage. This paper outlines a battery of tests that together may be used to assess the early-age thermal and autogenous shrinkage cracking risk of a concrete mixture. The effects of fly ash $\mathrm{CaO}$ content are examined as an example of the usefulness of this method.

\section{EXPERIMENTAL PROCEDURE}

The testing procedure used for this study for each concrete mixture can be divided up into two phases: the hydration characterization phase and the mechanical response phase. In the hydration characterization phase, semi-adiabatic calorimetry

ACI Materials Journal, V. 105, No. 2, March-April 2008

MS No. M-2006-443 received November 14, 2006, and reviewed under Institute publication policies. Copyright (C) 2008, American Concrete Institute. All rights reserved, including the making of copies unless permission is obtained from the copyright proprietors. Pertinent discussion including authors' closure, if any, will be published in the JanuaryFebruary 2009 ACI Materials Journal if the discussion is received by October 1, 2008. 
ACI member Kyle A. Riding is a Postdoctoral Researcher at the Swiss Federal Institute of Technology, Lausanne, Switzerland. He received his MS and PhD from the University of Texas at Austin, Austin, TX. He is a member of ACI Committee 201, Durability of Concrete.

ACI member Jonathan L. Poole is an Engineer at Wiss, Janney, Elstner Associates, Inc., Dallas, TX. He received a BS, MS, and PhD from the University of Texas at Austin. He is a member of ACI Committee 207, Mass Concrete, and 305, Hot Weather Concreting.

ACI member Anton K. Schindler is an Associate Professor in the Department of Civil Engineering at Auburn University, Auburn, AL. He received his MSE and PhD in civil engineering from the University of Texas at Austin. He is a member of ACI Committees 211 , Proportioning Concrete Mixtures; 231, Properties of Concrete at Early Ages; 237, Self-Consolidating Concrete; and E803, Faculty Network Coordinating Committee.

ACI member Maria C. G. Juenger is an Assistant Professor of civil, architectural, and environmental engineering at the University of Texas at Austin. She received her $\mathrm{PhD}$ in materials science and engineering from Northwestern University, Evanston, IL. She is a member of ACI Committees 201, Durability of Concrete; 231, Properties of Concrete at Early Ages; 236, Material Science of Concrete; and E802, Teaching Methods and Educational Materials.

Kevin J. Folliard, FACI, is an Associate Professor in the Department of Civil, Architectural, and Environmental Engineering at the University of Texas at Austin. He received his $P h D$ in civil engineering from the University of California at Berkeley, Berkeley, CA, in 1995. He is a member of ACI Committee 201, Durability of Concrete, 318, Concrete Building Code; and the ACI Publications Committee. He received the ACI Young Member Award for Professional Achievement in 2002.

is performed on the concrete mixture. The adiabatic heat generation curve parameters ${ }^{8}$ obtained for the mixtures are then used to simulate the temperature development of the mixture in a specific structural element, which are imposed on the tests conducted under phase two. Other researchers have performed cracking tests by simulating various-sized concrete members and boundary conditions. ${ }^{9-11}$ The center point of a simulated $1 \mathrm{~m}$ (39 in.) thick wall was chosen to allow for a large heat gain and, therefore, large differentiation between material behaviors. The temperature history of concrete in the simulated wall was calculated using a constant surface temperature to keep the calculations simple and allow for the simulation of normal, hot, or cold climates. The concrete fresh temperature can also be changed in the simulation to quantify the effects of concrete precooling on the mixture's cracking sensitivity. The advantage of this approach is that the configuration of the structural member and nature of the cementitious materials system will dictate the concrete temperature development in each test. This approach thus allows one to test the cracking sensitivity of the concrete under realistic conditions that the concrete may be exposed to during construction. The experiments reported in this paper were conducted with a fresh temperature and simulated wall surface temperature of $23^{\circ} \mathrm{C}\left(73^{\circ} \mathrm{F}\right)$.

The mechanical response of the concrete mixture is tested in phase two of the testing program. The second phase of

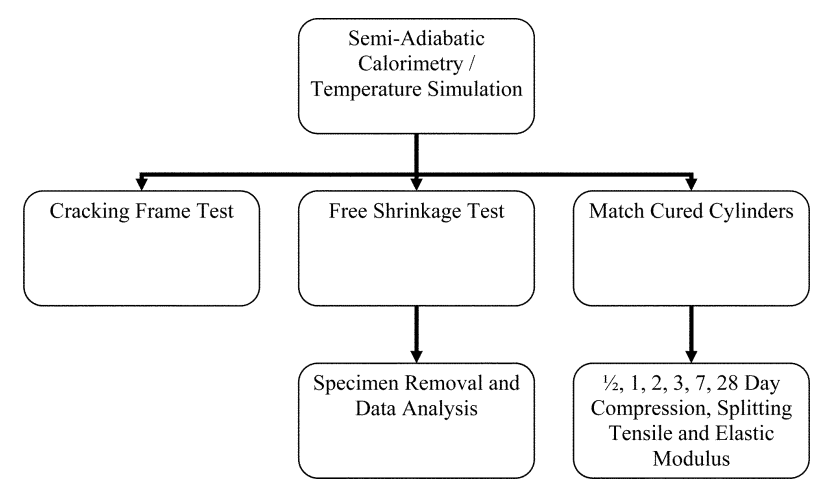

Fig. 1-Testing program summary. testing used in this testing regime allows for the quantification of the concrete mechanical property development, free thermal dilation, autogenous shrinkage, and early-age creep response. Figure 1 summarizes the testing sequence used.

The concrete uniaxial stress under restrained conditions is measured using a rigid cracking frame. ${ }^{12}$ Figure 2 shows a drawing of the rigid cracking frame and a picture of the test setup. A 150 x 150 x $1250 \mathrm{~mm}(6 \times 6 \times 49$ in.) concrete specimen is placed, consolidated, and cured in the rigid cracking frame. The formwork of the rigid cracking frame allows the temperature of the freshly placed concrete to be conditioned to simulate various structural elements. The temperature of the rigid cracking frame specimen is controlled using a programmable refrigerating/heating circulator that circulates a 50/50\% mixture of water and ethylene glycol through copper pipes in the formwork and cracking frame crosshead. The circulator is controlled based on the temperature in the middle of the cracking frame measured using a Type $\mathrm{T}$ thermocouple. The temperature in the concrete crossheads is also measured using Type $\mathrm{T}$ thermocouples. Because the temperature in the concrete is actively controlled, the difference between the temperature in the specimen middle and crosshead is generally within $0.5^{\circ} \mathrm{C}\left(0.9^{\circ} \mathrm{F}\right)$. If the concrete specimen does not crack after 96 hours, it is cooled at a rate of $1{ }^{\circ} \mathrm{C} /$ hour $\left(1.8^{\circ} \mathrm{F} /\right.$ hour $)$ to induce cracking in the concrete and to directly measure the concrete tensile strength. The temperature at which the concrete cracks is referred to as the cracking temperature. ${ }^{5}$ The lower the cracking temperature is, the better the concrete mixture resistance to thermal cracking will be. ${ }^{5}$
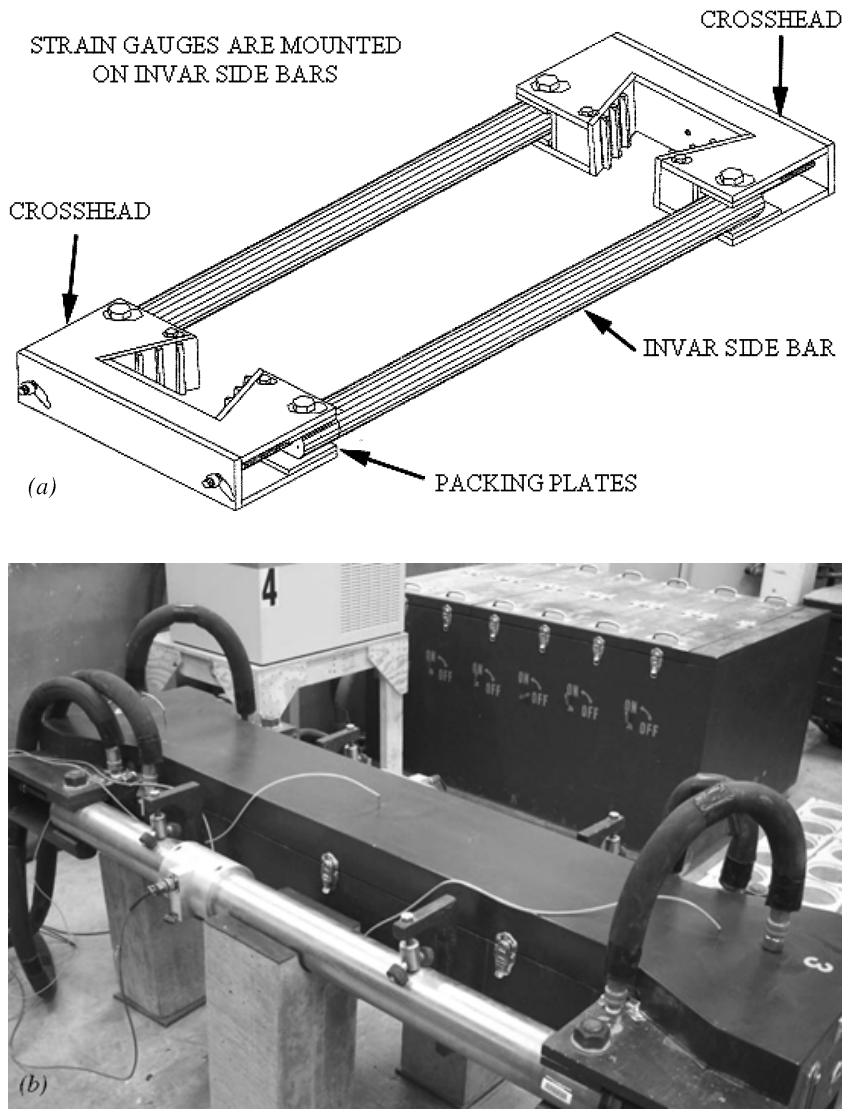

Fig. 2-Rigid cracking frame: (a) schematic of frame without crosshead braces and formwork; and (b) frame in use. ${ }^{13}$ 
The stress in the rigid cracking frame is monitored with strain gauges mounted on the $100 \mathrm{~mm}$ (4 in.) diameter restraining bars. The system is statically determinant, allowing for the calculation of the concrete stress from knowledge of the force in the very low coefficient of thermal expansion iron-nickel alloy steel bars. The force in the steel bars is calculated using the measured strain and the frame stiffness that is obtained through a calibration procedure. During the calibration procedure, a known axial load is applied to the frame while the steel bar strain is measured. The degree of restraint provided by the bars on the concrete can be calculated using Eq. (1)

$$
\delta=\frac{100}{1+\frac{E_{c} A_{c}}{E_{s} A_{s}}}
$$

where $\delta$ is the degree of restraint $(\%) ; E_{c}$ is the concrete elastic modulus $(\mathrm{MPa}) ; A_{c}$ is the concrete cross-sectional area $\left(\mathrm{m}^{2}\right) ; E_{S}$ is the restraining bar modulus (MPa); and $A_{s}$ is the restraining bars cross-sectional area $\left(\mathrm{m}^{2}\right)$. The temperature of the bars at the location of the strain gauges is measured using a resistance temperature detector (RTD) probe. The thermal movement of the restraining bars also needs to be subtracted from the measured strain to calculate the actual stress-induced strain in the bars, as shown in Eq. (2)

$$
\varepsilon_{T a d j}=\Delta T_{i b} \times \alpha_{i b} \times \delta
$$

where $\varepsilon_{\text {Tadj }}$ is the temperature-induced strain of the bar; $\Delta T_{i b}$ is the temperature change of the bar at the strain gauge $\left({ }^{\circ} \mathrm{C}\right)$; and $\alpha_{i b}$ is the coefficient of thermal expansion of the bar $\left(\mathrm{m} / \mathrm{m} /{ }^{\circ} \mathrm{C}\right)$.

A free shrinkage frame has been developed to measure the free thermal and autogenous dilation of the concrete mixture. It is advantageous to use a direct measurement of the concrete free shrinkage to eliminate errors that may come from using a constant coefficient of thermal expansion or an assumed autogenous shrinkage development. Figure 3 shows a diagram and picture of the free shrinkage frame. The free shrinkage specimen dimensions are $150 \times 150 \times 520 \mathrm{~mm}$ ( $6 \times 6 \times 20.4$ in.). The bottom bar is made of a very low coefficient of thermal expansion iron-nickel alloy, as well as the threaded rods that are embedded in the concrete. The threaded rod is screwed onto the linear potentiometer, which is then threaded onto a $25 \times 25 \mathrm{~mm}$ ( 1 x 1 in.) plate that is embedded in the concrete. The threaded rod is greased to allow for reuse. Two layers of plastic are used between the concrete and the formwork, with a petroleum-based lubricant applied under each layer, to reduce friction between the specimen and the formwork as much as possible. The copper pipes in the free-shrinkage frame's formwork are connected in series with the cracking frame and circulator to ensure that the free shrinkage frame's temperature stays within approximately $1{ }^{\circ} \mathrm{C}\left(1.8^{\circ} \mathrm{F}\right)$ of the temperature of the concrete in the rigid cracking frame. The temperature is recorded using two thermocouples. The free shrinkage is initialized and set to zero at initial setting as determined following ASTM C403, ${ }^{14}$ also using temperature-controlled specimens as will be described in the following. Special care should be taken to make sure that the plastic extends to the end of the specimen and folds up so that mortar does not get under the plastic and increase friction. The top surface is sealed with plastic and adhesive aluminum tape. The opening on the end plate is drilled larger than the rod to reduce friction between the rod and the plate when the rod moves. Grease is used to fill the remainder of the hole left by the threaded rod to prevent moisture loss. The hole in the top formwork was drilled larger than the thermocouples to ensure that no restraint is provided by the thermocouple probes. Silicone is used to seal the holes in the formwork where the thermocouples are inserted.

Twenty-four $100 \times 200 \mathrm{~mm}$ ( 4 × 8 in.) concrete cylinders are match-cured to the cracking frame temperature for mechanical property testing, as shown in Fig. 4. The concrete cylinders are placed in an insulated water bath immediately after finishing. The temperature of the water bath is controlled to within approximately $1{ }^{\circ} \mathrm{C}\left(1.8{ }^{\circ} \mathrm{F}\right)$ of the rigid cracking frame temperature by another $28 \mathrm{~L}\left(1 \mathrm{ft}^{3}\right)$ capacity refrigerating/heating circulator. The cylinders are tested at $1 / 2,1,2,3,7$, and 28 days for compressive strength, static modulus of elasticity, ${ }^{14}$ and splitting tensile strength. When a cylinder is removed from the water bath for testing,

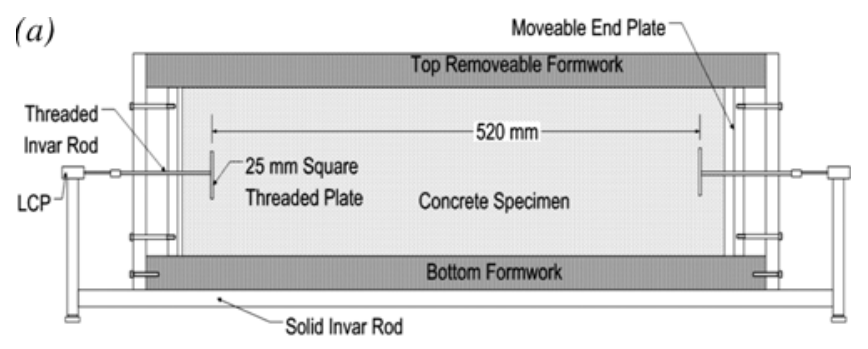

(b)

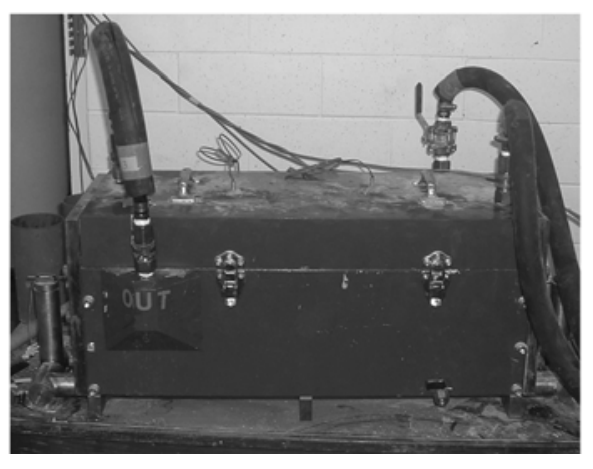

Fig. 3-Free shrinkage frame: (a) diagram; and (b) frame used for this project.

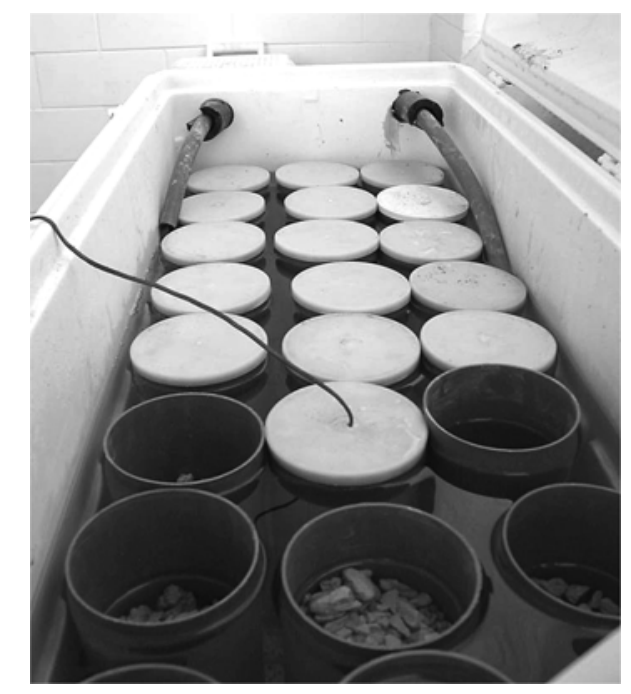

Fig. 4-Match-cured concrete cylinders. 
it is replaced with a dummy cylinder to maintain a constant water level. A water bath is also placed in series with the concrete cylinder water bath to hold specimens for testing the time of setting of concrete mixtures by penetration resistance in accordance with ASTM C403. ${ }^{15}$ When the match-cured time of setting specimens achieve initial set, the end plates in the free shrinkage rig are backed away from the concrete.

\section{Early-age concrete creep analysis}

The modulus of elasticity development, free thermal deformations, and autogenous deformation are used as inputs to predict the stress development of the concrete in the rigid cracking frame. The temperature distribution in the bar is also used to simulate the thermal movement of the bar with time and the corresponding change in the degree of restraint of the concrete. The temperature distribution in the bar may be approximated by using symmetry and the temperature distribution for a fin of circular cross section with an adiabatic end tip (this is the case for symmetry in the middle of the restraining bar because there would be no heat exchange in the middle of a symmetrical bar). Equations (3) through (6) show how the temperature distribution of a fin of uniform cross section with an adiabatic tip could be analytically simulated ${ }^{16}$

$$
\begin{gathered}
\frac{\theta}{\theta_{b}}=\frac{\cosh m(L-x)}{\cosh m L} \\
\theta=T-T_{\infty} \\
\theta_{b}=T_{b}-T_{\infty}
\end{gathered}
$$

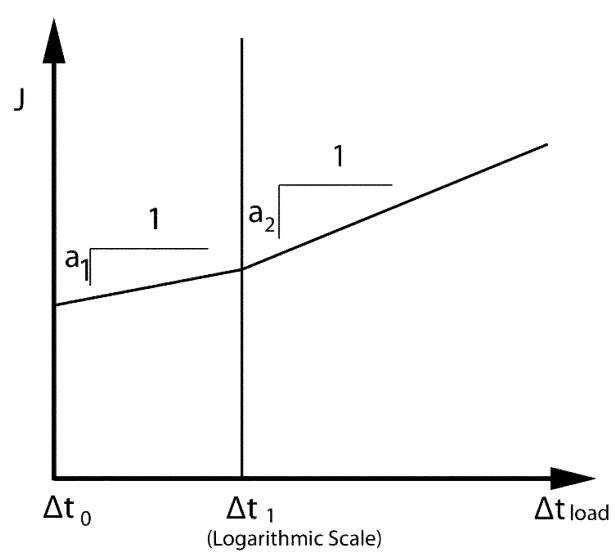

Fig. 5-Creep compliance J using linear logarithmic model (after Reference 17).

Table 1-Concrete mixture proportions

\begin{tabular}{c|c|c|c|c|c}
\hline \multirow{2}{*}{ Material } & \multicolumn{5}{|c}{ Mixture identification } \\
\cline { 2 - 6 } & Control & FA1 & FA2 & FA3 & FA4 \\
\hline Cement, $\mathrm{kg} / \mathrm{m}^{3}$ & 335 & 268 & 268 & 268 & 268 \\
\hline Fly ash, $\mathrm{kg} / \mathrm{m}^{3}$ & 0 & 67 & 67 & 67 & 67 \\
\hline Water, $\mathrm{kg} / \mathrm{m}^{3}$ & 141 & 141 & 141 & 141 & 141 \\
\hline Coarse aggregate, $\mathrm{kg} / \mathrm{m}^{3}$ & 1143 & 1131 & 1133 & 1136 & 1136 \\
\hline Fine aggregate, $\mathrm{kg} / \mathrm{m}^{3}$ & 762 & 753 & 753 & 759 & 760 \\
\hline Air content, \% & 2.4 & 2 & 2.3 & 1.9 & 2.5 \\
\hline
\end{tabular}

Note: $1 \mathrm{~kg} / \mathrm{m}^{3}=1.69 \mathrm{lb} / \mathrm{yd}^{3}$.

$$
m=|\sqrt{2 h / k r}|
$$

where $L$ is half the length of the rod (because symmetry is being exploited) (m); $x$ is the distance along the rod from the cracking frame crosshead $(\mathrm{m}) ; T$ is the temperature in the rod at location $x\left({ }^{\circ} \mathrm{C}\right) ; T_{b}$ is the temperature of the rod at the cracking frame crosshead $\left({ }^{\circ} \mathrm{C}\right) ; T_{\infty}$ is the ambient temperature $\left({ }^{\circ} \mathrm{C}\right) ; h$ is the convection coefficient $\left(\mathrm{W} / \mathrm{m}^{2} /{ }^{\circ} \mathrm{C}\right) ; k$ is the rod thermal conductivity $\left(\mathrm{W} / \mathrm{m} /{ }^{\circ} \mathrm{C}\right)$; and $r$ is the rod radius $(\mathrm{m})$.

Once the elastic strain is calculated, the creep response can then be calculated using the principle of superposition. ${ }^{6}$ The calculated stresses after creep can then be compared with the measured stresses. A regression analysis is used to determine the creep parameters that provide the best fit of the measured stresses. The procedure for calculating the early-age creep parameters by fitting creep constants to the measured concrete stresses in the rigid cracking frame assumes that creep in compression and tension are equal. In this paper, the linear logarithmic model (LLM), as developed by Larson, ${ }^{17}$ is used to model the creep behavior. The method models the creep compliance as two linear functions on a log scale, as shown in Fig. 5. Equations (7) and (8) show the creep compliance using the LLM ${ }^{17}$

$$
\Delta J\left(\Delta t_{\text {load }}, t_{0}\right)=
$$

$$
\begin{cases}a_{1}\left(t_{0}\right) \log \left(\frac{\Delta t_{\text {load }}}{\Delta t_{0}}\right) & \text { for } \Delta t_{0} \leq \Delta t_{\text {load }}<\Delta t_{1} \\ a_{1}\left(t_{0}\right) \log \left(\frac{\Delta t_{\text {load }}}{\Delta t_{0}}\right)+a_{2}\left(t_{0}\right) \log \left(\frac{\Delta t_{\text {load }}}{\Delta t_{0}}\right) & \text { for } \Delta t_{\text {load }} \geq \Delta t_{1}\end{cases}
$$

$$
a_{i}\left(t_{0}\right)=a_{i}^{\min }+\left(a_{i}^{\max }-a_{i}^{\min }\right) \times \exp \left(-\left(\frac{t_{0}-t_{s}}{t_{a i}}\right)^{n_{a i}}\right)
$$

for $i=1,2$, where $\Delta J$ is the increase in creep compliance $(1 / \mathrm{Pa})$; $\Delta t_{\text {load }}$ is the time from application of the load (days); $\Delta t_{0}$ is the time of load application (days), $\Delta t_{1}$ is the time limit that transitions between short-term and long-term creep (days), $t_{s}$ is the apparent setting time (days); $a_{i}^{\max }, a_{i}^{\min }, t_{a i}$, and $n_{a i}$ are fit parameters. Each of these parameters are defined and explained in detail elsewhere. ${ }^{17}$

\section{MATERIALS TESTED}

A total of five different concrete mixtures were tested using the procedure outlined previously. A Type I cement was used in all concrete mixtures tested. A No. 57 gradation $^{18}$ siliceous river gravel coarse aggregate and natural siliceous sand were used in all mixtures. The mixture proportions used in each test are shown in Table 1. Four different fly ashes with varying $\mathrm{CaO}$ content, two ASTM C618 Class F and two Class C fly ashes, ${ }^{19}$ were tested at a $20 \%$ replacement level by mass. The fly ash chemical composition and Blaine fineness are shown in Table 2. All mixtures were tested using a $w / \mathrm{cm}$ of 0.42 . All mixtures contained $4 \mathrm{oz} / \mathrm{cwt}$ of ASTM Type A low-range water reducing admixture. ${ }^{20}$

\section{RESULTS AND DISCUSSION}

The semi-adiabatic test results for each mixture were used to simulate the temperature at the middle of a $1 \mathrm{~m}$ (39 in.) thick wall with a constant surface temperature of $23^{\circ} \mathrm{C}\left(73^{\circ} \mathrm{F}\right)$. Figure 6 shows the temperature measured in the middle of the 
cracking frame specimens and the resulting stress development. All of the concrete mixtures containing fly ash show a significant reduction in heat of hydration, with the Class F fly ashes showing the most decrease. The penetration resistance values measured from the match-cured setting test specimens are shown in Fig. 7. All fly ashes tested show a retardation in setting compared with the control. The Class F ashes may retard setting due to a dilution of portland cement concentration. Both Class $\mathrm{C}$ fly ashes retard setting more than the Class F fly ashes. FA3 shows more retardation than the other fly ashes tested. Previous researchers have shown that Class $\mathrm{C}$ fly ashes can have different setting behaviors than Class $\mathrm{F}$ ashes, but results are highly variable. ${ }^{21}$ The cracking behavior of mixtures with significantly delayed settings may be quite different than that of mixtures measured in this paper. More extensive testing and caution is recommended when using mixtures with very long setting times. The cracking frame results (refer to Fig. 6(b)) show that all of the fly ashes tested lowered restraint stresses and improved cracking resistance. The Class F fly ashes lowered the cracking temperature by an average of $7.5^{\circ} \mathrm{C}\left(13.5^{\circ} \mathrm{F}\right)$, whereas the Class $\mathrm{C}$ fly ashes lowered the cracking temperature by an average of $4.2^{\circ} \mathrm{C}\left(7.6^{\circ} \mathrm{F}\right)$. Figure 8 shows the best-fit concrete splitting tensile strength development curves. It is significant to note that the mixtures containing Class F fly ash show the slowest strength gain rate, but the best cracking resistance as measured by the time to cracking and cracking temperature. The measured modulus values for all the concrete mixtures show similar modulus developments with time, indicating that the lower heat of hydration and increased creep are more influential parameters in reducing cracking. The cracking resistance that is lost by the reduced tensile strength gain is more than made up by the lowered thermal strain (caused by the lowered heat of hydration) and increased creep. The stress-to-splitting tensile strength ratio development with time was the quickest for the control mixture, but the fly ash mixture's development was only slightly lower, as shown in Fig. 9. The free thermal and autogenous dilation results are shown in Fig. 10. The fly ash mixtures showed considerable less expansion early on, probably because of the lowered heat of hydration during the first few hours of hydration during which time the coefficient of thermal expansion is higher. ${ }^{22-24}$

Creep parameters were fit from the stress, free shrinkage, and modulus development data using the LLM. ${ }^{17}$ A good fit of the stress data was achieved by adjusting only the $t_{a 1}$ parameter, as shown in Table 3. The magnitude of $a_{1}{ }^{\max }$, $a_{1}{ }^{\text {min }}$, and $a_{2}{ }^{\max }$ are as recommended by Larson. ${ }^{17}$ Figure 11

Table 2-Fly ash chemical composition and Blaine fineness

\begin{tabular}{c|c|c|c|c}
\hline \multirow{2}{*}{ Item } & \multicolumn{4}{|c}{ Fly ash identification } \\
\cline { 2 - 5 } & FA1 & FA2 & FA3 & FA4 \\
\hline Fly ash class & F & F & C & C \\
\hline $\mathrm{SiO}_{2}, \%$ & 56.63 & 51.69 & 37.83 & 33.31 \\
\hline $\mathrm{Al}_{2} \mathrm{O}_{3}, \%$ & 30.68 & 24.81 & 19.83 & 18.39 \\
\hline $\mathrm{Fe}_{2} \mathrm{O}_{3}, \%$ & 4.94 & 4.22 & 6.17 & 5.4 \\
\hline $\mathrm{CaO}, \%$ & 0.69 & 13.12 & 23.13 & 28.91 \\
\hline $\mathrm{MgO}, \%$ & 0.73 & 2.29 & 4.62 & 5.25 \\
\hline Total alkalis as $\mathrm{Na}_{2} \mathrm{O}, \%$ & 1.61 & 0.73 & 1.78 & 1.87 \\
\hline Blaine surface area, $\mathrm{m}^{2} / \mathrm{kg}$ & 147.3 & 165.5 & 348.4 & 299.9 \\
\hline
\end{tabular}

Note: $1 \mathrm{~m}^{2} / \mathrm{kg}=4.9 \mathrm{ft}^{2} / \mathrm{lb}$. shows the decrease in the $a_{1}$ (the slope of the first linear portion or short-term creep compliance) parameter with time. The creep compliance decreased faster with time in the
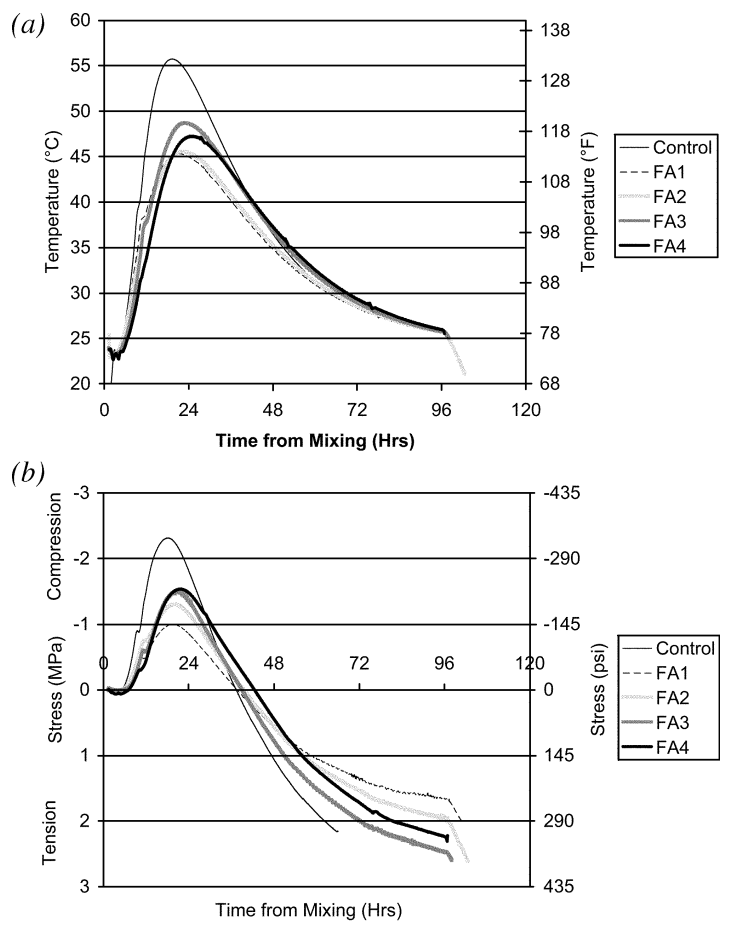

Fig. 6-Rigid cracking frame: (a) measured temperatures; and (b) measured stresses.

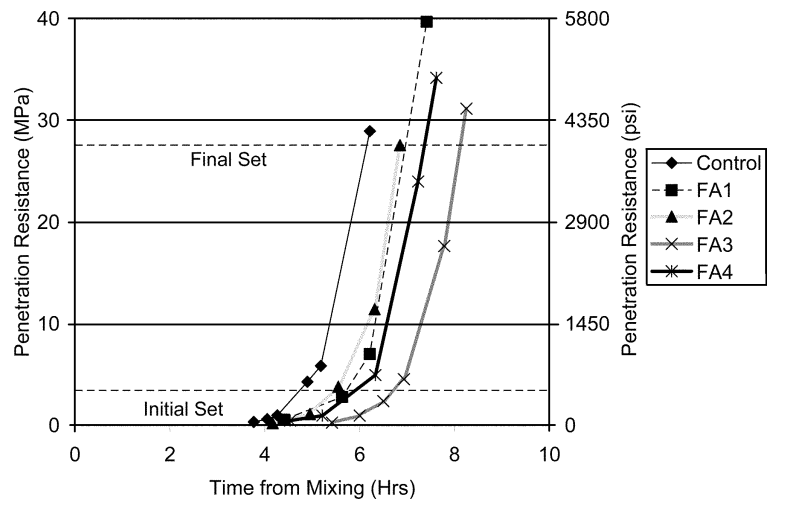

Fig. 7-Time of setting of concrete mixtures using ASTM C403.

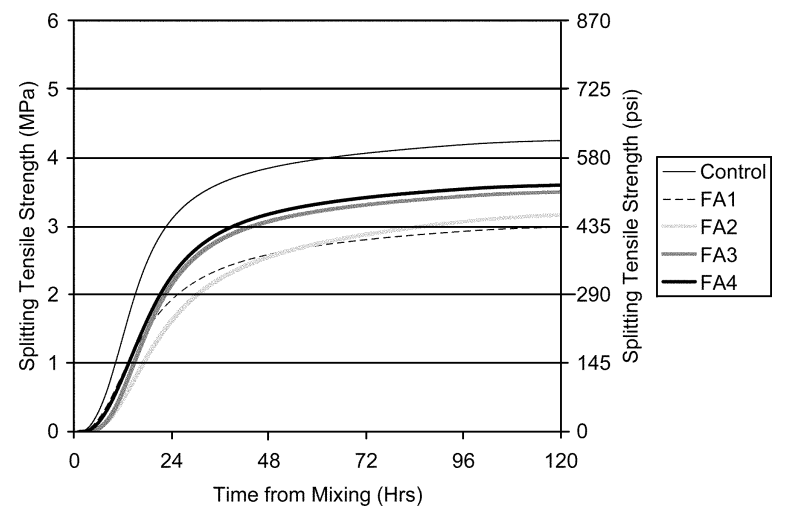

Fig. 8-Best-fit concrete splitting tensile strength development curves. 


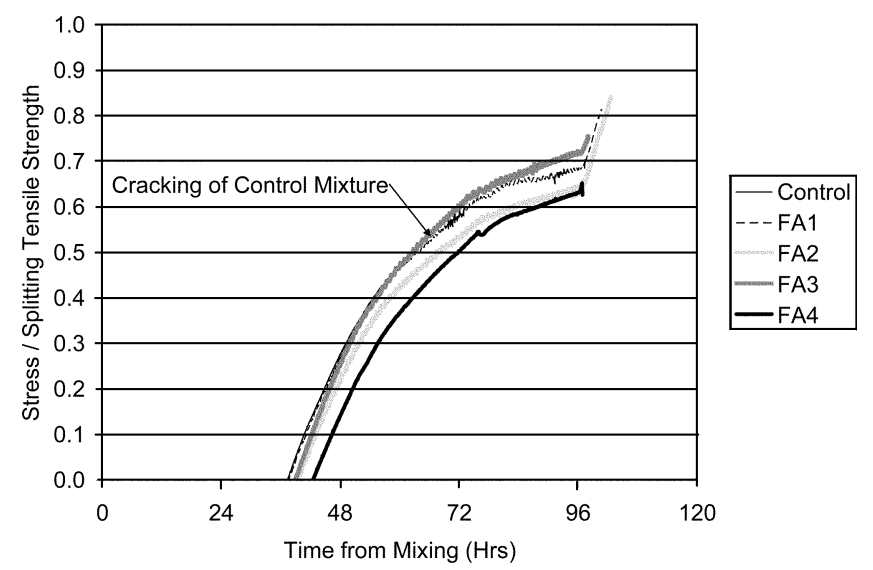

Fig. 9-Concrete stress/splitting tensile strength.

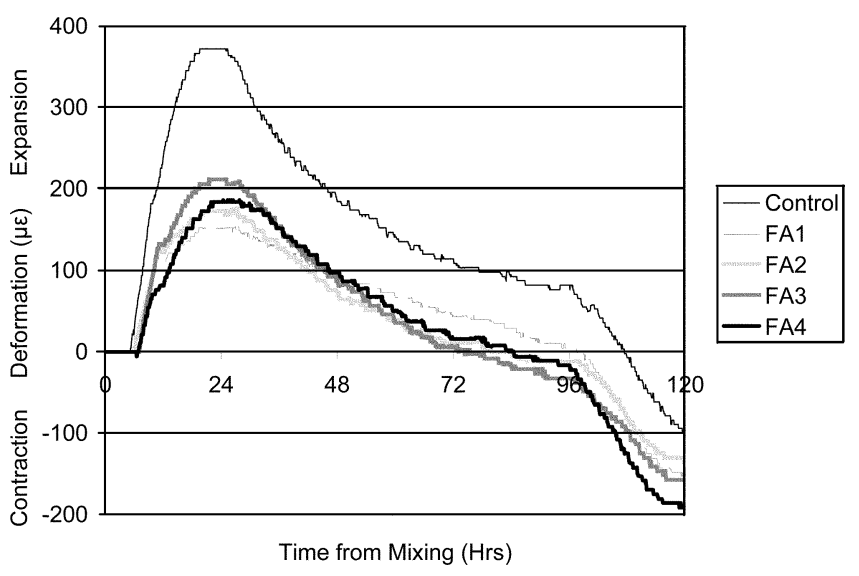

Fig. 10-Free thermal and autogeneous deformation.

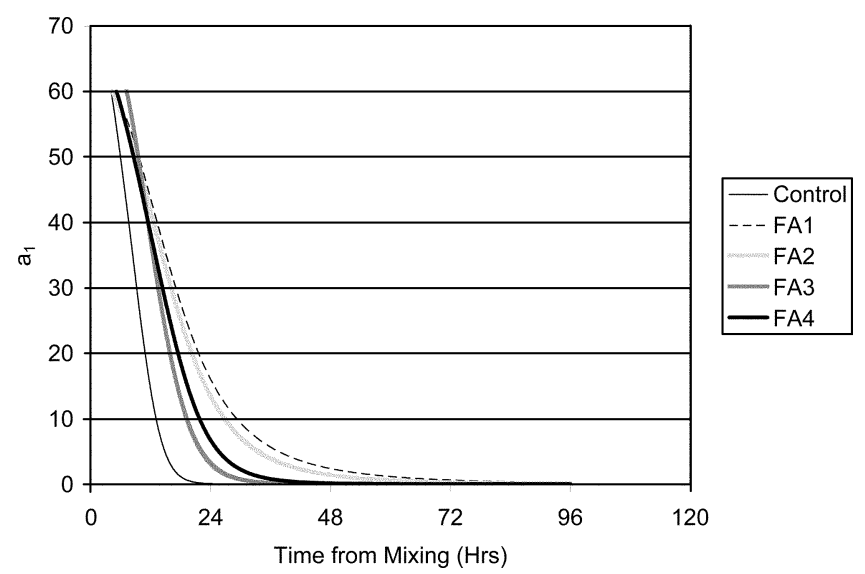

Fig. 11-Decrease in $\mathrm{a}_{1}$ parameter in linear logarithmic model. concrete mixtures that had a higher heat of hydration. The Class F fly ashes showed higher early age creep, which helped contribute to the increased cracking resistance.

A numerical investigation into the relative importance of early-age creep on the stress history was performed. Thermal stresses in a simulated cracking frame were calculated for the five mixtures using the creep parameters calculated and found in Table 3, the measured modulus development (using an equivalent age), and the temperature history recorded from the control mixture. The calculated stresses are shown in Fig. 12. In general, the higher the $a_{1}$ parameter is, the lower the early-age stresses will be. FA3 was an exception to this rule and had a lower early-age stress than FA4 even though the $a_{1}$ parameter was lower. This occurred because FA3 had a delayed setting. All of the mixtures were predicted to have higher tensile stresses than the control because of less beneficial precompression due to the increased early-age creep, but similar later age creep. Temperature effects on modulus and creep may give different actual results than that modeled. These numerical computations are not meant to imply that concrete containing fly ash increases the risk of cracking, only to illustrate the impact of the decrease in thermal strains. This simple numerical case study does show that the biggest impact on cracking resistance from the use of fly ash is the decrease in thermal movement. More research is needed on concrete containing fly ash at lower $w / \mathrm{cm}$ to investigate its effect on autogenous shrinkage.

\section{CONCLUSIONS}

A method for calculating concrete early-age creep parameters and determining the concrete resistance to cracking was presented. All fly ashes tested lowered the early-age

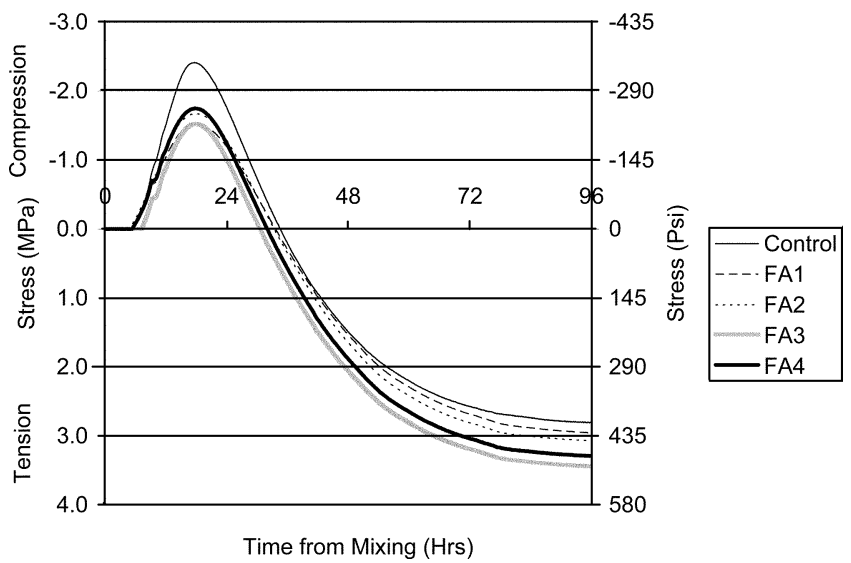

Fig. 12-Simulated concrete stress using same temperature history.

Table 3-Calculated concrete creep parameters using linear logarithmic method

\begin{tabular}{c|c|c|c|c|c|c|c|c}
\hline & \multicolumn{7}{|c}{ Creep parameters from Eq. 7 and 8} \\
\cline { 2 - 9 } Mixture ID & $t_{a 1}$, days & $n_{a 1}$ & $a_{1}{ }^{\min }\left(10^{-12} / \mathrm{Pa} \log \right)$ & $a_{1}{ }^{\max }\left(10^{-12} / \mathrm{Pa} \log \right)$ & $t_{a 2,}$ days & $n_{a 2}$ & $a_{2}^{\min }\left(10^{-12} / \mathrm{Pa} \log \right)$ & $a_{2}{ }^{\max }\left(10^{-12} / \mathrm{Pa} \log \right)$ \\
\hline Cement & 0.4 & 1.1 & 0.1 & 60 & 3 & 0.08 & 6 & 30 \\
\hline FA1 & 1.3 & 1.1 & 0.1 & 60 & 3 & 0.08 & 6 & 30 \\
\hline FA2 & 1.15 & 1.1 & 0.1 & 60 & 3 & 0.08 & 6 & 30 \\
\hline FA3 & 0.6 & 1.1 & 0.1 & 60 & 3 & 0.08 & 6 & 30 \\
\hline FA4 & 0.75 & 1.1 & 0.1 & 60 & 3 & 0.08 & 6 & 30 \\
\hline
\end{tabular}

Note: $10^{-12} / \mathrm{Pa} \log =6.9 \times 10^{-9} / \mathrm{psi} \log$. 
cracking risk of concrete. The concrete containing fly ash had a lower tensile strength development than the control mixture. This indicates that, given equal stress development, the concrete containing fly ash should crack sooner than the control mixture. The cracking tendency for concrete containing fly ash, however, was lower because the stresses were reduced by a lowered thermal strain (caused by a lowered heat of hydration) and increased early-age creep. In fact, the cracking tendency for concrete containing low calcium oxide fly ash was the lowest, even though its rate of tensile strength development was the slowest. It is the combined effect of creep, lower heat of hydration, modulus development, and tensile strength gain that defines the cracking risk. More testing needs to be performed on concrete containing fly ash at lower $w / \mathrm{cm}$ to investigate the effects of fly ash on autogenous shrinkage.

Further research is recommended to identify and quantify the effect of variables such as aggregate type, aggregate gradation, $w / \mathrm{cm}$, cement type, SCM type, and placement temperature on the cracking sensitivity of concrete.

\section{ACKNOWLEDGMENTS}

The authors wish to express their gratitude to the Texas Department of Transportation through Project 0-4563 for funding this research. The advice and support of R. Browne and T. Yarbrough of the Texas Department of Transportation is greatly appreciated. The guidance and assistance of R. Springenschmid and E. Gierlinger to develop the cracking frame test setup are appreciated.

\section{REFERENCES}

1. Emborg, M., "Models and Methods for Computation of Thermal Stresses," Prevention of Thermal Cracking in Concrete at Early Ages, RILEM Report 15, R. Springenschmid, ed., E\&FN Spon, London, UK, 1998, pp. 179-230.

2. van Breugel, K., "Prediction of Temperature Development in Hardening Concrete," Prevention of Thermal Cracking in Concrete at Early Ages, RILEM Report 15, R. Springenschmid, ed., E\&FN Spon, London, UK, 1998, pp. 51-75.

3. Lura, P.; van Breugel, K.; and Maruyama, I., "Effect of Curing Temperature and Type of Cement on Early-Age Shrinkage of HighPerformance Concrete," Cement and Concrete Research, V. 31, 2001, pp. 1867-1872.

4. Justnes, H.; Hammer, T.; Ardoullie, B.; Hendrix, E.; Van Gemert, D.; Overmeer, K.; and Sellevold, E., "Chemical Shrinkage of Cement Paste, Mortar and Concrete," Autogenous Shrinkage of Concrete, E. Tazawa, ed., E\&FN Spon, London, UK, 1999, pp. 211-220.

5. Springenschmid, R., and Breitenbücher, R., "Influence of Constituents, Mix Proportions and Temperature on Cracking Sensitivity of Concrete," Prevention of Thermal Cracking in Concrete at Early Ages, RILEM Report 15, R. Springenschmid, ed., E\&FN Spon, London, UK, 1998, pp. 40-50.

6. Bažant, Z., "Numerical Determination of Long-Range Stress History from Strain History in Concrete," Materials and Structures, RILEM, Paris, V. 5, No. 27, 1972, pp. 135-141.
7. Bažant, Z., and Chern, J., "Triple Power Law for Concrete Creep," Journal of Engineering Mechanics, V. 111, No. 1, 1985, pp. 63-83.

8. Schindler, A., and Folliard, K., "Heat of Hydration Models for Cementitious Materials," ACI Materials Journal, V. 102, No. 1, Jan.-Feb. 2005, pp. 24-33.

9. Westman, G., "Concrete Creep and Thermal Stresses," Doctoral Thesis, Luleå University of Technology, Division of Structural Engineering, 1999, $301 \mathrm{pp}$.

10. Kanstad, T.; Bjøntegaard, Ø.; Sellevold, E.; Hammer, T.; and Fidjestøl, P., "Effects of Silica Fume on Crack Sensitivity," Concrete International, V. 23, No. 12, Dec. 2001, pp. 53-59.

11. Schöppel, K.; Plannerer, M.; and Springenschmid, R., "Determination of Restraint Stresses and of Material Properties During Hydration of Concrete with the Temperature-Stress-Testing Machine," Thermal Cracking in Mass Concrete, RILEM Report 25, E\&FN Spon, London, UK, 1994, pp. 153-160.

12. Mangold, M., "Methods for Experimental Determination of Thermal Stresses and Crack Sensitivity in the Laboratory," Prevention of Thermal Cracking in Concrete at Early Ages, RILEM Report 15, R. Springenschmid, ed., E\&FN Spon, London, UK, 1998, pp. 26-39.

13. Whigham, J., "Evaluation of Restraint Stresses and Cracking in Early-Age Concrete with the Rigid Cracking Frame," master's thesis, Auburn University, AL, 2005, pp. 169 and 192.

14. ASTM C469, "Standard Test Method of Static Modulus of Elasticity and Poisson's Ratio of Concrete in Compression," ASTM International, West Conshohocken, PA, 2002, 4 pp.

15. ASTM C403, "Standard Test Method for Time of Setting of Concrete Mixtures by Penetration Resistance," ASTM International, West Conshohocken, PA, 2005, 6 pp.

16. Incropera, F., and Dewitt, D., Fundamentals of Heat and Mass Transfer, John Wiley \& Sons, Inc., New York, 2002, 981 pp.

17. Larson, M., "Thermal Crack Estimation in Early Age ConcreteModels and Methods for Practical Application," doctoral thesis, Luleå University of Technology, Division of Structural Engineering, 2003, 190 pp.

18. ASTM C33, "Standard Specification for Concrete Aggregates," ASTM International, West Conshohocken, PA, 2003, 11 pp.

19. ASTM C618, "Standard Specification for Coal Fly Ash and Raw or Calcined Natural Pozzolan for Use in Concrete," ASTM International, West Conshohocken, PA, 2003, 3 pp.

20. ASTM C 494, "Standard Specification for Chemical Admixtures for Concrete," ASTM International, West Conshohocken, PA, 1999, 9 pp.

21. Naik, T. R., and Singh, S., "Influence of Fly Ash on Setting and Hardening Characteristics of Concrete Systems," ACI Materials Journal, V. 94, No. 5, Sept.-Oct. 1997, pp. 355-360.

22. Yamakawa, H.; Nakauchi, H.; Kita, T.; and Onuma, H., "A Study of the Coefficient of Thermal Expansion of Concrete," Transactions of the Japan Concrete Institute, V. 8, 1986, pp. 111-118.

23. Glisic, B., "Fibre Optic Sensors and Behavior in Concrete at Early Age," Thesis No. 2186, Swiss Federal Institute of Technology, Lausanne, Switzerland, 2000, p. 113.

24. Schöppel, K., and Springenschmid, R., "The Effect of Thermal Deformation, Chemical Shrinkage and Swelling on Restraint Stresses in Concrete at Early Ages," Thermal Cracking in Mass Concrete, RILEM Report 25, E\&FN Spon, London, UK, 1994, pp. 213-220. 